\title{
DEVELOPMENT AND STABILITY EVALUATION OF VAGINAL SUPPOSITORY CONTAINING GLYCYRRHIZA GLABRA L. FOR THE TREATMENT OF CANDIDA ALBICANS INFECTION
}

\author{
SASITHORN SIRILUN ${ }^{1}$, BHAGAVATHI SUNDARAM SIVAMARUTHI ${ }^{1}$, PERIYANAINA KESIKA ${ }^{1}$, NOPPAWAT \\ PENGKUMSRI ${ }^{1,2}$, NUCHAREE TUNTISUWANNO ${ }^{1}$, KHONTAROS CHAIYASUT T ${ }^{3,4}$, SARTJIN PEERAJAN ${ }^{4}$, \\ CHAIYAVAT CHAIYASUT ${ }^{1 *}$
}

\begin{abstract}
${ }^{1}$ Innovation Center for Holistic Health, Nutraceuticals and Cosmeceuticals, Faculty of Pharmacy, Chiang Mai University, Chiang Mai 50200, Thailand. ${ }^{2}$ Faculty of Pharmacy, Huachiew Chalermprakiet University, Samutprakan 10540, Thailand. ${ }^{3}$ Institute of Research and Development, Chiang Mai Rajabhat University, Chiang Mai 50300, Thailand. ${ }^{4}$ Health Innovation Institute, Chiang Mai 50200, Thailand. Email: chaiyavat@gmail.com
\end{abstract}

Received: 14 March 2018, Revised and Accepted: 04 April 2018

ABSTRACT

Objective: The present study assessed the antioxidant activity, phytochemical content, and anti-Candida albicans property of ethanolic extract of Glycyrrhiza glabra L. (licorice). In addition, suppository formula (SF) was developed with licorice extract (LE), and the stability of SF was evaluated.

Methods: The total phenolic and flavonoid content was measured by colorimetric methods. 2, 2'-azino-bis-3-ethylbenzthiazoline-6-sulfonic acid (ABTS), ferric reducing antioxidant power (FRAP), inhibition of lipid peroxidation (LPO), nitric oxide (NO), and superoxide (SO) radical scavenging assays were performed to evaluate antioxidant property. Antimicrobial activity was determined by plating method. The active principle was determined by high-performance liquid chromatography method.

Results: The licorice sample was extracted with $95 \%$ ethanol, and $26.91 \pm 1.35 \%$ of yield was observed. The LE contains phenolic acids ( $167.70 \pm 3.18$ mg gallic acid equivalent/g extract), flavonoids (162.53 $\pm 9.95 \mathrm{mg}$ quercetin equivalent/g extract), and glabridin (3.90 $\pm 0.05 \mathrm{mg} / \mathrm{g}$ extract). LE exhibited the scavenging activity in terms of $810.53 \pm 25.37 \mu \mathrm{M}$ of Trolox equivalent/mg of extract, $165.04 \pm 5.10 \mu \mathrm{M}$ of $\mathrm{FeSO}_{4}$ equivalent/mg of extract, and $3750.35 \pm 1.25,68.25 \pm 0.07$, and $511 \pm 0.80 \mu \mathrm{M}$ of Trolox equivalent/mg of extract in ABTS, FRAP, LPO, NO, and SO assays, respectively. About $\geq 62.50$, $\geq 125$, and $\geq 250 \mu \mathrm{g} / \mathrm{mL}$ of LE was recorded as minimal inhibitory concentration against C. albicans, Lactobacillus casei, and Lactobacillus acidophilus, respectively. The SF was formulated and the stability was evaluated. The activity and color of SFs did not differ on storage. Moreover, no spot formation was observed.

Conclusion: The SF with LE could be the safe therapeutic strategy for the treatment of candida infection in vaginal region.

Keywords: Antimicrobial activity, Candida albicans, Glycyrrhiza glabra L., Suppository formula, Licorice, Ethanolic extract.

(C) 2018 The Authors. Published by Innovare Academic Sciences Pvt Ltd. This is an open access article under the CC BY license (http://creativecommons. org/licenses/by/4. 0/) DOI: http://dx.doi.org/10.22159/ajpcr.2018.v11i7.25927

\section{INTRODUCTION}

Microbial species are ubiquitous and extensively spread all over the surroundings, especially in human body parts. The association of microbial community and the human body is native, and most of the microbes are nonpathogenic, and being considered as normal flora or commensal flora. Nevertheless, some microbial species becomes lethal to the host system because of the extended biomass of particular species, especially fungal species $[1,2]$. The fungal infections are the fourth leading cause of microbial infections, particularly by Candida species such as Candida albicans, Candida glabrata, Candida krusei, Candida lusitaniae, Candida parapsilosis, and Candida tropicalis $[3,4]$

Women are the frequent victim of Candida infection in the form of vaginal candidiasis (VC), and VC is the second most common vaginal infection in developed countries like the USA, and C. albicans is the leading cause of VC, whereas non-albicans Candida infection also has been increased gradually [5]. The symptoms of fungal infections are not always noticeable; the severity and incubation period of infection varies based on an individual's immunity. Some of the common cause of fungal infections is a sedentary lifestyle, drugs, improper diet, stress, etc. [6]. The VC is associated with strong itching, swelling, vulval erythema, vulval edema, irritation, and white discharges.

Citronellal has significant antifungal activity against $C$. tropicalis, a nonalbicans Candida species that cause vulvovaginal candidiasis (VVC)
[7]. The leaf extracts of Pimenta dioica showed anti-C. albicans activity [8]. The modified flavonoids from Citrus limetta exhibited increased antifungal activity against $C$. albicans [9]

Although several studies reported the bioactive compounds, the drug delivery is the precious step in the treatment of any diseases; in particular, the treatment of $\mathrm{VC}$ is done by oral and suppository supplementation of drugs. The suppository treatments are relatively effective since the drugs are delivered in proximity to the target tissues. Vito et al. [10] reported the antimicrobial activity of vaginal suppository formulation (SF) with tea tree oil against Candida spp. The plantbased SFs for the treatment of VC are found to be not promising, and it requires in-depth research on finding new active compounds from plant materials against $C$. albicans.

Licorice is one of the ancients, still widely used therapeutic herb, and it is used either alone or in combination with another phytomedicine. Licorice and its bioactive compounds are reported for antiinflammatory, antiviral, antihepatotoxic, antibacterial activity, and also act as an expectorant and emollient in cosmetics [11,12]. Glabridin, a well-studied prenylated isoflavone of G. glabra L. and reported for many biological activities such as estrogen-like activity, inhibition of cytochrome, binding with proliferator-activated receptor gamma, and melanogenesis [13]. The antidiabetic nature and weakening of fat accumulation properties of the glabridin have been reported using 
diabetes and obese mice models $[14,15]$. The recent study reported the anti-Candida property of G. glabra L. against several Candida species and strains, and also explained the anti-Candida biofilm activity against C. glabrata and C. tropicalis strains [16].

Thus, the present study evaluated the anti-C. albicans property of ethanolic extract of licorice. Antioxidant activity, and phytochemical content of the selected active extract has also been evaluated. The study also deals with the development of the SF with active extract, assessment of the physicochemical content and stability of the SF.

\section{METHODS}

\section{Sample collection and extraction}

G. glabra L. (licorice) were collected from the local farmers of Chiang Mai, Thailand, and the species was confirmed with herbarium specimens of Faculty of Pharmacy, Chiang Mai University, Thailand. The samples were dried at $60^{\circ} \mathrm{C}$ for $24 \mathrm{~h}$ and milled to a fine powder. Then, $1 \mathrm{~kg}$ of the sample was macerated in $2 \mathrm{~L}$ of $95 \%$ ethanol for $48 \mathrm{~h}$ and filtrated through Whatman No. 1 filter paper before evaporation at $50^{\circ} \mathrm{C}$ using vacuum evaporator (Buchi Rotavapor RE-120). The percentage of yield was calculated (Equation 1) and stored at $-20^{\circ} \mathrm{C}$ until use.

Yield $(\%)=$ (weight of the extract $(\mathrm{g}) /$ weight of the licorice powder $(\mathrm{g})) \times 100$

\section{Estimation of phytochemical content}

Total phenolic and flavonoid content

The total phenolic and flavonoid content of licorice extract (LE) was determined as described previously by Pengkumsri et al. [17]. The total phenolic and flavonoid content was denoted as mg of gallic acid equivalent (mg GAE) per g of extract, and mg of quercetin equivalent (mg QE) per g of extract, respectively.

\section{Determination of free radical scavenging property of extracts}

The antioxidant property of extracts was assessed by 2, 2'-azino-bis-3ethylbenzthiazoline-6-sulfonic acid (ABTS), ferric reducing antioxidant power (FRAP), inhibition of lipid peroxidation (LPO), nitric oxide (NO), and superoxide ( $\mathrm{SO}^{-}$) radical scavenging assays as described by Pengkumsri et al. [17].

\section{C. albicans inhibition assays}

The agar dilution assay was performed to assess the anti-Candida activity of extracts. In brief, C. albicans was cultured in Sabouraud dextrose broth $(\mathrm{SDB})$ at $37^{\circ} \mathrm{C}$ for $24 \mathrm{~h}$ and diluted to achieve $1.5 \times 10^{5} \mathrm{cells} / \mathrm{ml}$ of broth. Then, $100 \mu \mathrm{L}$ of cell suspension was plated by mixing with $10 \mathrm{ml}$ of Sabouraud dextrose soft agar. About $6 \mathrm{~mm}$ sized, agar wells were created, and $100 \mu \mathrm{L}$ of LE was introduced. The inhibition zone was measured after incubation at $37^{\circ} \mathrm{C}$ for $24-48 \mathrm{~h} .100 \mu \mathrm{L}$ of ciclopirox olamine $(10 \mathrm{mg} / \mathrm{mL})$ (synthetic antifungal agent), SDB, and dimethyl sulfoxide (DMSO) was used as positive, negative, and vehicle control, respectively [18].

The minimal inhibitory concentration (MIC) of LE against $C$. albicans was studied by modified broth dilution method. Briefly, C. albicans was raised as $1.5 \times 10^{5}$ cells $/ \mathrm{mL}$ in SDB and mixed with serially diluted test extracts in a 96 -well plate, followed by incubating at $37^{\circ} \mathrm{C}$ for $24 \mathrm{~h}$. The MIC concentration was determined by spectrophotometric analysis of the growth of $C$. albicans at $600 \mathrm{~nm}$. $100 \mu \mathrm{L}$ of ciclopirox olamine $(10 \mathrm{mg} / \mathrm{mL}), \mathrm{SDB}$, and DMSO was used as positive, negative, and vehicle control, respectively [19].

Effect of LE on the growth of representative strains of normal microbial flora

MIC assay was performed to assess the antimicrobial activity of LE against Lactobacillus casei and Lactobacillus acidophilus. Strains were cultured in de Man, Rogosa, and Sharpe (MRS) broth to achieve the cell density of $1.5 \times 10^{8}$ cell $/ \mathrm{mL} .100 \mu \mathrm{L}$ of ampicillin $(2 \mathrm{mg} / \mathrm{mL})$,
MRS, and DMSO was used as positive, negative, and vehicle control, respectively.

\section{Development and evaluation of SF}

Development of suppository base and SF with $L E$

The raw materials such as polyethylene glycol (PEG)-6000, PEG-400, propylene glycol, glycerin, and water were used. These ingredients were mixed in different combination and assessed for the hardness, distribution of ingredients, and disintegration time. The different concentration of LE $(1,2$, and $5 \%)$ was added with a selected best combination of base formula (PEG-6000, PEG-400, propylene glycol, glycerin, and water). The prepared SFs were studied [20] for the physical appearance (color, surface, and silkiness), variations in weight (mean of four decimal weighing of 20 samples), hardness (by cutter shearing), distribution of ingredients (by spot and migration of ingredients), melting point, and disintegration time (time required for complete dissociation of formula at $37^{\circ} \mathrm{C}$ ).

\section{Stability evaluation}

The stability of SF was measured as per the guideline of Center for Drug Evaluation and Research, U.S.A (ICH Q1A (R2)) and Department of Health and Human Services Food and Drug Administration. The stability at different temperature $\left(5 \pm 3,30 \pm 2\right.$, and $\left.40 \pm 2^{\circ} \mathrm{C}\right)$ with $75 \%$ of relative humidity for 3 months was studied. The changes in phytochemicals content, C. albicans inhibition property, and antioxidant property of the formula were assessed.

\section{Determination of active compounds}

Glabridin and 18- $\beta$-glycyrrhetinic acid content extract have been assessed by high-performance liquid chromatography technique. The extract was analyzed using isocratic condition (Shimadzu LC 10AV, Japan) with Shodex ${ }^{\circledR}$ RP-C18 (250 mm $\times 4.6$ mm, $5 \mu \mathrm{m}$, Japan) column. The isocratic condition of mobile phase was prepared with $70 \%$ of acetonitrile with $30 \%$ of $0.05 \%$ trifluoroacetic acid at a flow rate of $1.0 \mathrm{~mL} / \mathrm{min}$. The UV detector (Shimadzu LC 10AV, Japan) was set at $240 \mathrm{~nm}$ to analyze a linear range of glabridin $(0.01-0.05 \mathrm{mg} / \mathrm{mL})$ and 18 -glycyrrhetinic acid $(0.02-0.10 \mathrm{mg} / \mathrm{mL})$ and LE.

\section{Statistical analysis}

The results were determined in triplicates to confirm the reproducibility. The data were given as mean \pm standard deviation. Analysis of variance was performed using statistical SPSS software version 17 (Chicago, SPSS Inc., U.S.A). The least significant difference post hoc test was performed to analyze the significant differences in antioxidant activities and $\mathrm{p}<0.05$ was considered as statistically significant.

\section{RESULTS AND DISCUSSION}

The licorice sample was extracted with $95 \%$ ethanol and $26.91 \pm 1.35 \%$ of yield was achieved. Then, the LE was found to contain $167.70 \pm 3.18 \mathrm{mg}$ GAE/g extract and $162.53 \pm 9.95 \mathrm{mg}$ QE/g extract of phenolic and flavonoids content, respectively. The major active compounds of the licorice, such as glabridin and 18- $\beta$-glycyrrhetinic acid, were assessed in the LE and only glabridin $(3.90 \pm 0.05 \mathrm{mg} / \mathrm{g}$ extract $)$ was detected (Table 1). The antioxidant nature of the LE has been evaluated by various assays such as ABTS, FRAP, LPO, NO, and SO. LE showed the scavenging

Table 1: The yield and phytochemical content of ethanolic extract of Glycyrrhiza glabra L.

\begin{tabular}{lll}
\hline S. No & Content & Values \\
\hline 1 & Percentage of yield (\%) & $26.91 \pm 1.35$ \\
2 & Total phenolic content (mg GAE/g extract) & $167.70 \pm 3.18$ \\
3 & Total flavonoid content (mg QE/g extract) & $162.53 \pm 9.95$ \\
4 & Glabridin content (mg/g extract) & $3.90 \pm 0.05$ \\
5 & $18-\beta$-Glycyrrhetinic acid content & ND \\
& (mg/g extract) & \\
\hline
\end{tabular}

GAE: Gallic acid equivalent, QE: Quercetin equivalent, ND: Not detected 
activity in terms of $165.04 \pm 5.10 \mu \mathrm{M}$ of $\mathrm{FeSO}_{4}$ equivalent/mg of extract and $810.53 \pm 25.37,3750.35 \pm 1.25,68.25 \pm 0.07$, and $511 \pm 0.80 \mu \mathrm{M}$ of Trolox equivalent/mg of extract in FRAP, ABTS, LPO, NO, and SO assays, respectively (Table 2). The data indicated that LE contains more free radical scavenging compounds, especially glabridin.

The studies suggested that nystatin vaginal suppositories were effective to treat VVC caused by C. glabrata and fluconazole-resistant Candida, whereas nystatin suppositories were less effective against $C$. albicans. Moreover, miconazole nitrate $(1200 \mathrm{mg})$ vaginal suppository was active as oral fluconazole $(150 \mathrm{mg}$ ) for the treatment of severe VVC $[21,22]$. The VVC in diabetes patients is commonly caused by C. glabrata and C. tropicalis. The boric acid vaginal suppositories based therapy cure the VVC in diabetes patients when compared to the oral fluconazole treatment, and boric acid suppositories are superior for the acute treatment of VVC $[23,24]$. The 14-day use of vaginal suppositories prepared with amphotericin B $(50 \mathrm{mg})$ cures the non-albicans VVC effectively [5]. Whereas, the impact of the use of antibiotic as suppositories on normal microbial flora has not been reported in detail. In the present study, the MIC of LE against C. albicans and representative normal flora such as $L$. casei and L. acidophilus were studied. About $\geq 62.50, \geq 125$, and $\geq 250 \mu \mathrm{g} / \mathrm{mL}$ of LE was recorded as MIC for C. albicans, L. casei, and L. acidophilus, respectively. The results of the present study also proved the anti-Candida property of LE, and

Table 2: Antioxidant activities of the licorice extract

\begin{tabular}{ll}
\hline $\begin{array}{l}\text { Antioxidant } \\
\text { assays }\end{array}$ & Mean \pm SD \\
\hline ABTS & $810.53 \pm 25.37 \mu \mathrm{M}$ of Trolox equivalent/mg of extract \\
FRAP & $165.04 \pm 5.10 \mu \mathrm{M}$ of FeSO equivalent/mg of extract \\
LPO & $3,750.35 \pm 1.25 \mu \mathrm{M}$ of Trolox equivalent/mg of extract \\
NO & $68.25 \pm 0.07 \mu \mathrm{M}$ of Trolox equivalent/mg of extract \\
SO & $511 \pm 0.80 \mu \mathrm{M}$ of Trolox equivalent/mg of extract \\
\hline
\end{tabular}

ABTS-2: 2'-azino-bis-3-ethylbenzthiazoline-6-sulfonic acid, FRAP: Ferric reducing antioxidant power, LPO: Inhibition of lipid peroxidation, NO: Nitric oxide, SO: Superoxide radical scavenging assay the data indicated that the LE extract has not affected the representative normal microbial flora in vitro, which revealed that the use of LE in SF is safe and effective against infection in terms of antioxidant potential (Table 2) and antifungal nature (Table 3).

The desired quality of the base material, which is used in the SF preparation, is amorphous solid at room temperature, whereas, at body temperature $\left(35-37^{\circ} \mathrm{C}\right)$, it should melt and facilitates the release of active compounds. The base materials are stable, nonirritating, and miscible with water and vaginal secretions. Oleaginous (triglycerides and cocoa butter [the obroma oil]) and water-soluble (PEG and glycerinated gelatin) bases are commonly used. The base of SF was made with different combinations of PEG6000, PEG400, water, propylene glycol, and glycerin at various concentrations (Table 4).

The dimension of the SF was about $25 \mathrm{~mm} \times 10 \mathrm{~mm}$. The suitability of base material was assessed in three diverse categories such as hardness, distribution, and disintegration time ( $\mathrm{min}$ ). The combination of PEG6000, PEG400, water, propylene glycol, and glycerin at the ratio of 40:30:10:10:10 was found to be the best base material for SF. The optimum hardness, good distribution, and 20 min of disintegration time were observed in formula F6 (Table 4).

Four types of SFs were prepared with selected base (F6) and different concentration of $(1,2$, and 5\%) LE (Table 5). The SFs were assessed for the physical appearance, weight (g), hardness, distribution, melting point, and disintegration time. The formula " $\mathrm{B}$ " was found to be the optimum composition for the SF with LE extract, which contains $2 \%$ of LE. The weight, melting temperature, and disintegration time of formula "B" was $2.45 \pm 0.03 \mathrm{~g}, 34.33 \pm 0.58^{\circ} \mathrm{C}$, and $27.40 \pm 0.70 \mathrm{~min}$, correspondingly (Table 6).

The stability of the SF with LE was assessed after the storage of samples at different temperature for 3 months as per the guideline of ICH Q1A (R2) Center for Drug Evaluation and Research, U.S., Department of Health and Human Services Food and Drug Administration. The MIC value $(\geq 31.25 \mu \mathrm{g} / \mathrm{mL}$ ) and color of SFs did not differ on storage. Moreover, no spot formation was observed (Table 7).

Table 3: Minimal inhibitory concentration of fresh LE and LE loaded suppository formula (stored at different conditions for 3 months) against tested microbes

\begin{tabular}{|c|c|c|c|}
\hline \multirow[t]{2}{*}{ Samples } & \multicolumn{3}{|c|}{ Minimal inhibitory concentrations } \\
\hline & C. albicans & L. casei & L. acidophilus \\
\hline DMSO & $\geq 125.00 \mu \mathrm{L} / \mathrm{mL}$ & $\geq 500 \mu \mathrm{L} / \mathrm{mL}$ & $\geq 500 \mu \mathrm{L} / \mathrm{mL}$ \\
\hline Ciclopirox olamine (positive control; anti-yeast) & $\geq 15.625 \mu \mathrm{g} / \mathrm{mL}$ & - & - \\
\hline Ampicillin (positive control; antibacteria) & - & $\geq 31.25 \mu \mathrm{g} / \mathrm{mL}$ & $\geq 31.25 \mu \mathrm{g} / \mathrm{mL}$ \\
\hline & $\geq 62.50 \mu \mathrm{g} / \mathrm{mL}$ & $\geq 125 \mu \mathrm{g} / \mathrm{mL}$ & $\geq 250 \mu \mathrm{g} / \mathrm{mL}$ \\
\hline \multicolumn{4}{|l|}{ After 3 months of storage at different temperature } \\
\hline SFLE (stored at $-20^{\circ} \mathrm{C}$ ) & $\geq 31.25 \mu \mathrm{g} / \mathrm{mL}$ & $\geq 125 \mu \mathrm{g} / \mathrm{mL}$ & $\geq 250 \mu \mathrm{g} / \mathrm{mL}$ \\
\hline SFLE (stored at $4^{\circ} \mathrm{C}$ ) & $\geq 31.25 \mu \mathrm{g} / \mathrm{mL}$ & $\geq 125 \mu \mathrm{g} / \mathrm{mL}$ & $\geq 250 \mu \mathrm{g} / \mathrm{mL}$ \\
\hline SFLE (stored at $25^{\circ} \mathrm{C}$ ) & $\geq 31.25 \mu \mathrm{g} / \mathrm{mL}$ & $\geq 125 \mu \mathrm{g} / \mathrm{mL}$ & $\geq 250 \mu \mathrm{g} / \mathrm{mL}$ \\
\hline SFLE (stored at $40^{\circ} \mathrm{C}$ ) & $\geq 62.50 \mu \mathrm{g} / \mathrm{mL}$ & $\geq 250 \mu \mathrm{g} / \mathrm{mL}$ & $\geq 500 \mu \mathrm{g} / \mathrm{mL}$ \\
\hline
\end{tabular}

SFLE: Suppository formula with licorice extract, LE: Licorice extract, DMSO: Dimethyl sulfoxide, C. albicans: Candida albicans, L. casei: Lactobacillus casei,

L. acidophilus: Lactobacillus acidophilus

Table 4: Different combination of base material and assessment of favorable conditions for the optimal preparation of suppository base formula

\begin{tabular}{|c|c|c|c|c|c|c|c|c|}
\hline \multirow[t]{2}{*}{ Formula } & \multicolumn{5}{|c|}{ Concentration (\%) } & \multicolumn{3}{|c|}{ Assessed parameters } \\
\hline & PEG6000 & PEG400 & Water & Propylene glycol & Glycerin & Hardness & Distribution & Disintegration time (min) \\
\hline F1 & 50 & 30 & 20 & - & - & ++++ & Poor & $\sim 15$ \\
\hline $\mathrm{F} 2$ & 50 & 30 & - & 20 & - & +++ & Poor & $\sim 25$ \\
\hline F3 & 50 & 30 & - & - & 20 & +++ & Poor & $\sim 25$ \\
\hline F4 & 40 & 20 & 10 & 20 & 10 & + & Very poor & $\sim 25$ \\
\hline F5 & 40 & 20 & 20 & 20 & 0 & - & Poor & $>30$ \\
\hline F7 & 40 & 30 & 20 & 10 & 0 & - & Poor & $\sim 25$ \\
\hline
\end{tabular}

PEG: Polyethylene glycol 


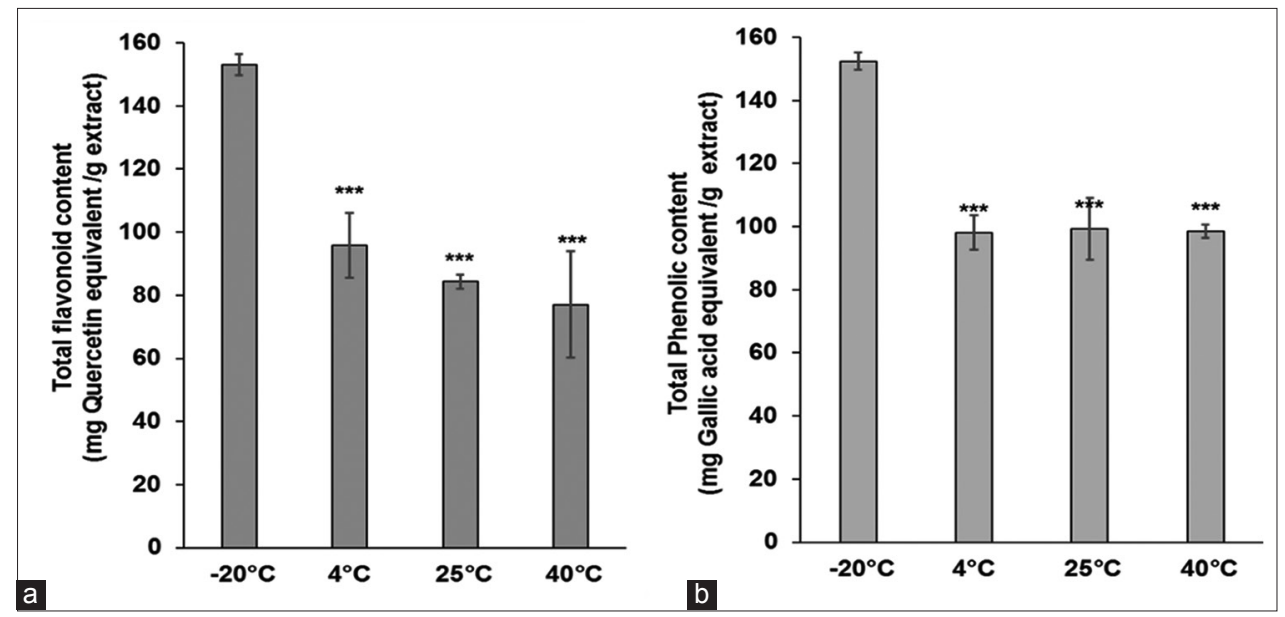

Fig. 1: The total flavonoid (a) and phenolic (b) content of suppository formula at different storage temperatures

Table 5: Formulation of suppository formula with different concentration of Glycyrrhiza glabra L. extract

\begin{tabular}{lllllll}
\hline \multirow{2}{*}{ Formula } & \multicolumn{2}{l}{ Concentration (\%) } & & & \\
\cline { 2 - 7 } & PEG6000 & PEG400 & Propylene glycol & Glycerin & Water & Licorice extract \\
\hline Base & 40 & 30 & 10 & 10 & 10 & 0 \\
A & 40 & 30 & 10 & 10 & 9 & 1 \\
B & 40 & 30 & 10 & 10 & 8 & 2 \\
C & 40 & 30 & 10 & 5 & 5 \\
\hline
\end{tabular}

PEG: Polyethylene glycol

Table 6: Evaluation of suppository formula with different concentration of Glycyrrhiza glabra L. extract

\begin{tabular}{|c|c|c|c|c|c|c|}
\hline \multirow[t]{2}{*}{ Formula } & \multicolumn{6}{|l|}{ Evaluation } \\
\hline & Physical appearance & Weight (g) & Hardness & Distribution & Melting point $\left({ }^{\circ} \mathrm{C}\right)$ & Disintegration time (min) \\
\hline Base & Good & $2.40 \pm 0.05$ & ++ & Good & $33.50 \pm 0.87$ & $25.20 \pm 1.03$ \\
\hline B & Good & $2.45 \pm 0.03$ & ++ & Good & $34.33 \pm 0.58$ & $27.40 \pm 0.70$ \\
\hline $\mathrm{C}$ & Poor & $2.47 \pm 0.05$ & +++ & Poor & $34.55 \pm 0.62$ & $30.75 \pm 0.81$ \\
\hline
\end{tabular}

+: Delicate, ++: Optimum, +++: Hard

Table 7: The stability assessment of selected suppository formula with Glycyrrhiza glabra L. extract after 3 months of storage

\begin{tabular}{llll}
\hline Condition & MIC $(\boldsymbol{\mu g} / \mathbf{m L})$ & Color & Uniformity \\
\hline MS & $\geq 125.00 \mu \mathrm{L}$ & - & - \\
Ciclopirox olamine & $>78.125$ & - & - \\
SFLE (stored at $\left.-20^{\circ} \mathrm{C}\right)$ & $\geq 31.25$ & Orange & Yes \\
SFLE (stored at $\left.4{ }^{\circ} \mathrm{C}\right)$ & $\geq 31.25$ & Orange & Yes \\
SFLE (stored at $\left.25^{\circ} \mathrm{C}\right)$ & $\geq 31.25$ & Orange & Yes \\
SFLE (stored at $\left.40^{\circ} \mathrm{C}\right)$ & $\geq 31.25$ & Orange & Yes \\
\hline
\end{tabular}

SFLE: Suppository formula with licorice extract

The total flavonoid and phenolic content of the SF were reduced concerning the storage temperature. The flavonoid concentration was reduced as $153.15 \pm 3.32,95.84 \pm 10.35,84.3 \pm 2.25$, and $77.08 \pm 16.87 \mathrm{mg}$ $\mathrm{QE} / \mathrm{g}$ of extract, when stored at $-20,4,25,40^{\circ} \mathrm{C}$, respectively. Likewise, the phenolic concentration was reduced as $152.15 \pm 2.71$, $98.11 \pm 5.42$, $99.28 \pm 9.90$, and $98.53 \pm 2.0 \mathrm{mg} \mathrm{GAE} / \mathrm{g}$ of extract, when stored at $-20,4$, $25,40^{\circ} \mathrm{C}$, respectively (Fig. 1 ).

The antioxidant property of the SFs was estimated by five different assays such as FRAP, ABTS, LPO, NO, and SO, after storage and found that the storage at more than $25^{\circ} \mathrm{C}$ significantly affected the quality of the SFs regarding the free radical scavenging property. The scavenging properties were reduced from $146.84 \pm 0.46 \mathrm{mg}$ of $\mathrm{FeSO}_{4}$ equivalent/g of extract and $775 \pm 112.29,3550.64 \pm 17.46,64.14 \pm 0.02$, and $490.77 \pm 1.90 \mathrm{mg}$ of Trolox equivalent/g of extract to $129.32 \pm 0.79 \mathrm{mg}$ of $\mathrm{FeSO}_{4}$ equivalent/g of extract and $569.33 \pm 14.24,2261.77 \pm 456.89$, $58.79 \pm 0.27$, and $472.41 \pm 14.15 \mathrm{mg}$ of Trolox equivalent/g of extract, after 3 months of storage at $40^{\circ} \mathrm{C}$ (Fig. 2).

The perfect SF should be non-toxic, non-irritating, and stable during storage. The SFs were active against $C$. albicans and relatively inert against tested Lactobacillus. The antioxidant nature was preserved during the storage of SF preparation at $4^{\circ} \mathrm{C}$ for 3 months. Room temperature affected the free radical scavenging nature but not the anti-Candida property of active compounds.

\section{CONCLUSION}

The developed SF with LE was stable, non-toxic, and non-irritating in nature and active against $C$. albicans. Further, clinical studies are required to confirm the activity of developed SFs in real situation. In future, the SF could be in market, after the successful clinical trials.

\section{ACKNOWLEDGMENT}

Authors gratefully acknowledge the Chiang Mai University grant (CMUgrant) for the support and also acknowledge the Faculty of Pharmacy, Chiang Mai University, Thailand, for the necessary provision. All the authors wish to acknowledge the National Science and Technology Development Agency for the support. 


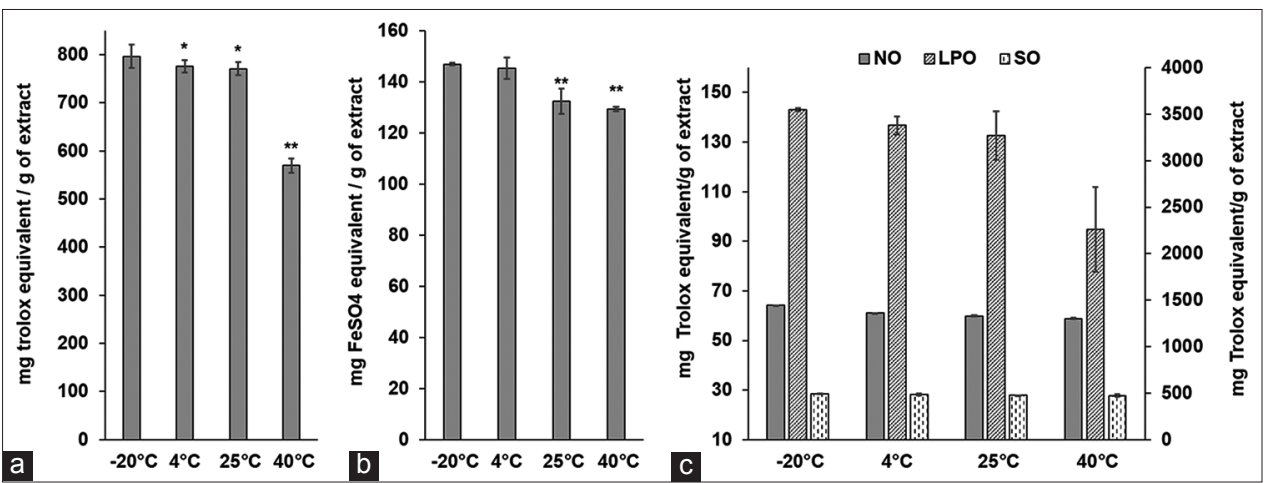

Fig. 2: The antioxidant property of suppository formula at different storage temperatures. (a) 2, 2'-azino-bis-3-ethylbenzthiazoline-6sulfonic acid, (b) ferric reducing antioxidant power, and (c) nitric oxide, inhibition of lipid peroxidation and superoxide assays

\section{AUTHOR'S CONTRIBUTIONS}

CC involved in the study design, experiments, review, and finalization of the manuscript. BSS and PK contributed to data analysis, manuscript preparation, and critical revision of the manuscript. SS, NP, KC, NT, and SP are responsible for wet lab experiments, data collection, and analysis. All the authors agree with the content of the manuscript.

\section{CONFLICTS OF INTEREST}

There are no conflicts of interest.

\section{REFERENCES}

1. Blanco JL, Garcia ME. Immune response to fungal infections. Vet Immunol Immunopathol 2008;125:47-70.

2. Brunke S, Hube B. Two unlike cousins: Candida albicans and C. glabrata infection strategies. Cell Microbiol 2013;15:701-8.

3. Pierce GE. Pseudomonas aeruginosa, Candida albicans, and devicerelated nosocomial infections: Implications, trends, and potential approaches for control. J Ind Microbiol Biotechnol 2005;32:309-18

4. Tsai PW, Chen YT, Hsu PC, Lan CY. Study of Candida albicans and its interactions with the host: A mini review. Biomedicine 2013;3:51-64.

5. Phillips AJ. Treatment of non-albicans Candida vaginitis with amphotericin B vaginal suppositories. Am J Obstet Gynecol 2005; 192:2009-13

6. Devasagayam TP, Tilak JC, Boloor KK, Sane KS, Ghaskadbi SS, Lele RD. Free radicals and antioxidants in human health: Current status and future prospects. J Assoc Phys India 2004;52:794-804.

7. Medeiros CI, Silva DD, Filho GG, Filho AA, Lima ED. Activity anti-c. Tropicalis and effects of the combination of (s)-(-)-citronellal with four antifungal applied in vulvovaginal candidiasis. Int J Pharm Pharm Sci 2016;8:347-51.

8. Bhat A, Raveesha KA. Antifungal activity of Pimenta dioica (L.) Merril an aromatic medicinal tree. Int J Pharm Pharm Sci 2016;8:92-5.

9. Muzna S, Divya D, Kamat SD, Kamat DV. Antifungal activity of lipase modified flavonoids from Citrus limetta. Int J Pharm Pharm Sci 2014;6:116-8.

10. Vito MD, Mattarelli P, Modesto M, Girolamo A, Ballardini M, Tamburro A, et al. In vitro activity of tea tree oil vaginal suppositories against Candida spp. and probiotic vaginal microbiota. Phytother Res 2015;29:1628-33.

11. Fatima A, Gupta VK, Luqman S, Negi AS, Kumar JK, Shanker K, et al. Antifungal activity of Glycyrrhiza glabra extracts and its active constituent glabridin. Phytother Res 2009;23:1190-3.

12. Lucas RM, editor. Nature's Medicines: The Folklore, Romance, and Value of Herbal Remedies. New York: Parker Pub Co. West Nyack; 1966.

13. Rebhun JF, Glynn KM, Missler SR. Identification of glabridin as a bioactive compound in licorice (Glycyrrhiza glabra L.) extract that activates human peroxisome proliferator-activated receptor gamma $(\operatorname{PPAR} \gamma)$. Fitoterapia 2015;106:55-61.

14. Nakagawa $K$, Kishida $H$, Arai N, Nishiyama T, Mae T. Licorice flavonoids suppress abdominal fat accumulation and increase in blood glucose level in obese diabetic KK-A(y) mice. Biol Pharm Bull 2004;27:1775-8

15. Ahn J, Lee H, Jang J, Kim S, Ha T. Anti-obesity effects of glabridin-rich supercritical carbon dioxide extract of licorice in high-fat-fed obese mice. Food Chem Toxicol 2013;51:439-45.

16. Martins N, Ferreira IC, Henriques M, Silva S. In vitro anti-candida activity of Glycyrrhiza glabra L. Ind Crops Prod 2016;83:81-5.

17. Pengkumsri N, Chaiyasut C, Saenjum C, Sirilun S, Peerajan S, Suwannalert $\mathrm{P}$, et al. Physicochemical and antioxidative properties of black, brown and red rice varieties of northern Thailand. Food Sci Technol Campinas 2015;35:331-8.

18. Sales MD, Costa HB, Fernandes PM, Ventura JA, Meira DD. Antifungal activity of plant extracts with potential to control plant pathogens in pineapple. Asian Pac J Trop Biomed 2016;6:26-31

19. Bussmann RW, Malca-García G, Glenn A, Sharon D, Chait G, Díaz D, et al. Minimum inhibitory concentrations of medicinal plants used in Northern Peru as antibacterial remedies. J Ethnopharmacol 2010;132:101-8

20. Nicoara AC, Cazacincu RG, Lupuleasa D, Miron DS, Radulescu FR. Formulation and in vitro release testing of rectal suppositories containing nimesulide. Farmacia 2015;63:111-7.

21. Fan S, Liu X, Wu C, Xu L, Li J. Vaginal nystatin versus oral fluconazole for the treatment for recurrent vulvovaginal candidiasis. Mycopathologia 2015;179:95-101

22. Fan S, Liu X, Liang Y. Miconazole nitrate vaginal suppository $1,200 \mathrm{mg}$ versus oral fluconazole $150 \mathrm{mg}$ in treating severe vulvovaginal candidiasis. Gynecol Obstet Invest 2015;80:113-8.

23. Ray D, Goswami R, Banerjee U, Dadhwal V, Goswami D, Mandal P, et al. Prevalence of Candida glabrata and its response to boric acid vaginal suppositories in comparison with oral fluconazole in patients with diabetes and vulvovaginal candidiasis. Diabetes Care 2007;30:312-7.

24. Ray D, Goswami R, Dadhwal V, Goswami D, Banerjee U, Kochupillai N. Prolonged (3-month) mycological cure rate after boric acid suppositories in diabetic women with vulvovaginal candidiasis. J Infect 2007;55:374-7. 